\title{
Autoantibodies Neutralizing Type I Interferons in 20\% of COVID-19 Deaths in a French Hospital
}

\author{
Angélique Chauvineau-Grenier ${ }^{1}(1) \cdot$ Paul Bastard $^{2,3} \cdot$ Antoine Servajean $^{4} \cdot$ Adrian Gervais $^{2,5} \cdot$ Jérémie Rosain $^{2,5}$. \\ Emmanuelle Jouanguy ${ }^{2,4} \cdot$ Aurélie Cobat $^{2,3} \cdot$ Jean-Laurent Casanova ${ }^{2,3,6} \cdot$ Benjamin Rossi $^{7}$
}

Received: 16 September 2021 / Accepted: 19 December 2021 / Published online: 27 January 2022

(c) The Author(s), under exclusive licence to Springer Science+Business Media, LLC, part of Springer Nature 2021

\begin{abstract}
Recent studies reported the presence of pre-existing autoantibodies (auto-Abs) neutralizing type I interferons (IFNs) in at least $15 \%$ of patients with critical COVID-19 pneumonia. In one study, these auto-Abs were found in almost $20 \%$ of deceased patients across all ages. We aimed to assess the prevalence and clinical impact of the auto-Abs to type I IFNs in the SeineSaint-Denis district, which was one of the most affected areas by COVID-19 in France during the first wave. We tested for the presence of auto-Abs neutralizing type I IFNs in a cohort of patients admitted for critical COVID-19 pneumonia during the first wave in the spring of 2020 in the medicine departments at Robert Ballanger Hospital, Aulnay sous Bois. We found circulating auto-Abs that neutralized $100 \mathrm{pg} / \mathrm{mL}$ IFN- $\alpha 2$ and/or IFN- $\omega$ in the plasma (diluted 1/10) of 7.9\% (11 of 139) of the patients hospitalized for critical COVID-19. The presence of neutralizing auto-Abs was associated with an increased risk of mortality, as these auto-Abs were detected in $21 \%$ of patients who died from COVID-19 pneumonia. Deceased patients with and without auto-Abs did not present overt clinical differences. These results confirm both the importance of type I IFN immunity in host defense against SARS-CoV-2 infection and the usefulness of detection of auto-Abs neutralizing type I IFNs in the management of patients.
\end{abstract}

Keywords Autoantibodies $\cdot$ type I interferons $\cdot$ COVID-19 $\cdot$ mortality

Angélique Chauvineau-Grenier angelique.grenier@ght-gpne.fr

1 Medical Biology Department, Robert Ballanger Hospital, Aulnay-Sous-Bois, France

2 Laboratory of Human Genetics of Infectious Diseases, Necker Branch, INSERM U1163, Necker Hospital for Sick Children, Paris, France

3 St. Giles Laboratory of Human Genetics of Infectious Diseases, Rockefeller Branch, The Rockefeller University, New York, NY, USA

4 University of Paris, UFR de Médecine, site Xavier Bichat, Paris, France

5 University of Paris, Imagine Institute, Paris, France

6 Howard Hughes Medical Institute, New York, NY, USA

7 Department of Internal Medicine, Robert Ballanger Hospital, Aulnay-Sous-Bois, France

\section{Introduction}

Since the onset of the COVID-19 pandemic in December 2019, at least 220 million people have been infected, and most likely many more. Nevertheless, only about $10 \%$ of these individuals developed hypoxemic COVID-19 pneumonia (severe or critical in about $3 \%$ of cases). There have been at least 5 million deaths, and most likely closer to 8-10 million. The clinical spectrum of SARS-CoV-2 infection is therefore vast, ranging from silent infection to lethal disease. A few epidemiological risk factors have been identified. The most important one is age, with a risk of life-threatening disease doubling every 5 years. Gender as well as several other risk factors have been described (e.g., obesity) but with relatively modest effects $[1,2]$. In each demographic category, however, there remains vast inter-individual clinical variability.

Recent studies showed the important role of type I Interferons (IFNs) in protective immunity against SARS-CoV-2. Inborn errors of type I IFNs immunity were described in patients with life threatening COVID-19. Rare inborn errors 
of autosomal genes controlling Toll-like receptor 3 (TLR3) and interferon regulatory factor 7 (IRF7)-dependent type I IFNs immunity were initially described [3] and more recently X-linked recessive TLR7 deficiency [4]. These inborn errors impair the production or amplification of type I IFNs in response to SARS-CoV-2. Deficiency of the TLR3 pathway incriminated pulmonary epithelial cells, while that of the TLR7 pathway incriminated plasmacytoid dendritic cells.

Interestingly, several studies showed that at least $10 \%$ of patients with life threatening (critical) COVID-19 pneumonia presented autoantibodies (auto-Abs) neutralizing type I IFNs, mostly the thirteen individual IFN- $\alpha$ and IFN- $\omega$ [5]. These auto-Abs were present before infection by SARSCoV-2 in the patients tested and in $0.33 \%$ of uninfected controls from before the pandemic. They were not detected in patients with asymptomatic or mild SARS-CoV-2 infection. They were also shown to block the anti viral activity of correspondent type I IFNs against SARS-CoV-2 in vitro and in vivo [5].These findings were replicated in other cohorts in Amsterdam, Madrid, San Francisco, Lyon, and New Haven [6-13].

Recently, auto-Abs neutralizing lower, more physiological concentrations of type I IFNs $(100 \mathrm{pg} / \mathrm{mL}$, in $1 / 10$ dilutions of plasma) were detected in 15 to $20 \%$ of patients with critical COVID-19, notably in more than $20 \%$ of critical patients over 80 years of age. When also considering autoAbs to IFN- $\beta$, they were present in about $20 \%$ of deceased patients across all ages [14]. Surprisingly, the study of more than 34,000 individuals showed that the prevalence of these auto-Abs in the general population increases with age, notably after the age of $70(4 \%)$, providing an explanation for the increased risk of severe COVID-19 with age [14].

In this context, we aimed to assess the prevalence and clinical impact of the auto-Abs to type I IFNs in SeineSaint-Denis department, which was one of the most affected areas by COVID-19 in France during the first wave of the pandemic [15]. We thus tested for the presence of auto-Abs to type I IFNs neutralizing different doses in a cohort of patients admitted for critical COVID-19 pneumonia during the first wave in the spring of 2020. Moreover, a commercial ELISA kit for the determination of anti-IFN- $\alpha 2$ auto-Abs was also evaluated.

\section{Materials and Methods}

\section{Study Population}

A cohort of 246 patients admitted for critical COVID-19 pneumonia was constituted in Robert Ballanger Hospital, Aulnay sous Bois, France, during the first wave of the pandemic in order to assess factors associated with clinical outcomes in patients hospitalized for COVID-19 [16].

This study was approved by a research ethics committee and was registered on clinicaltrials.gov (NCT04366206).

It included patients which, after going to the emergency room, were hospitalized in medicine departments dedicated to treat COVID-19 patients. Severity criteria required a pulse oxygen saturation $(\mathrm{SpO} 2) \leq 96 \%$ despite oxygen support $\geq 6 \mathrm{~L} / \mathrm{min}$ with oxygen mask, for more than $6 \mathrm{~h}$. All patients therefore had "critical" COVID-19 pneumonia [14, 17]. Some of these patients required an invasive mechanical ventilation and a transfer to an intensive care unit (ICU) during their hospitalization.

From this cohort of 246 patients, 139 patients were retrospectively selected because of an available serum sample that was collected during the acute phase of disease and stored in the laboratory sample collection. The studied population included 86 men and 53 women; median age was 66 years (range: $21-92$ years), and $15 \%$ of the patients was over the age of 80 years. For some of patients, serum sample was also collected about 1 year after infection.

\section{Detection of Anti-Cytokine Auto-Abs by Gyros and ELISA}

Biological serum samples were analyzed for the determination of anti-IFN- $\alpha$ and anti-IFN- $\omega$ auto-Abs by Gyros technology as previously described [14].

Cytokines, recombinant human (rh)IFN- $\alpha 2$ (Milteny Biotec, ref. number 130-108-984) or rhIFN- $\omega$ (Merck, ref. number SRP3061), were first biotinylated with EZ-Link Sulfo-NHS-LC-Biotin (Thermo Fisher Scientific, cat. number A39257), according to the manufacturer's instructions, with a biotin-to-protein molar ratio of 1:12. The detection reagent contained a secondary antibody, Alexa Fluor 647 goat anti-human IgG (Thermo Fisher Scientific, ref. number A21445) diluted in Rexxip F (Gyros Protein Technologies, ref. number P0004825; 1/500 dilution of the $2 \mathrm{mg} / \mathrm{mL}$ stock to yield a final concentration of $4 \mu \mathrm{g} / \mathrm{mL}$ ). Buffer PBS-T $0.01 \%$ and Gyros Wash buffer (Gyros Protein Technologies, ref. number P0020087) were prepared according to the manufacturer's instructions. Plasma or serum samples were then diluted $1 / 100$ in PBS-T $0.01 \%$ and tested with the Bioaffy 1000 CD (Gyros Protein Technologies, ref. number P0004253) and the Gyrolab X-Pand (Gyros Protein Technologies, ref. number P0020520). Cleaning cycles were performed in $20 \%$ ethanol.

Moreover, a commercially available ELISA kit (Human Anti-IFN alpha ELISA Kit, Thermo Fisher Scientific, ref number BMS217, hereafter referred to as "ELISA") was also used for the quantitative detection of human anti-IFN- $\alpha 2$ auto-Abs. In brief, microwells that were coated with recombinant human IFN- $\alpha$ subtype $2 \mathrm{c}$ were incubated with 1:5 
dilutions of serum samples from the patients for $2 \mathrm{~h}$ at room temperature. Plates were thoroughly washed. Horseradish peroxidase (HRP)-conjugated human IFN- $\alpha$ (subtype 2c) protein was added and plates were incubated for $1 \mathrm{~h}$ at room temperature and washed. Substrate solution reactive with HRP was added and a colored product was formed in proportion to the amount of human anti-IFN- $\alpha 2$ present in the sample or standard. The reaction was terminated by addition of acid and absorbance was measured at $450 \mathrm{~nm}$.

\section{Functional Evaluation of Anti-Cytokine Auto-Abs}

The blocking activity of anti-IFN- $\alpha 2$, anti-IFN- $\omega$, and antiIFN- $\beta$ auto-Abs was determined with a reporter luciferase activity as previously described [14].

Briefly, HEK293T cells were transfected with a plasmid containing the Firefly luciferase gene under the control of the human ISRE promoter in the pGL4.45 backbone, and a plasmid constitutively expressing Renilla luciferase for normalization (pRL-SV40). Cells were transfected in the presence of the X-tremeGene9 transfection reagent (SigmaAldrich, ref. number 6365779001) for $24 \mathrm{~h}$. Cells in Dulbecco's modified Eagle medium (DMEM, Thermo Fisher Scientific) supplemented with $2 \%$ fetal calf serum (FCS) and $10 \%$ healthy control or patient serum/plasma (after inactivation at $56^{\circ} \mathrm{C}$, for $20 \mathrm{~min}$ ) were either left unstimulated or were stimulated with IFN- $\alpha 2$ (Milteny Biotec, ref. number 130-108-984), IFN- $\omega$ (Merck, ref. number SRP3061), at $10 \mathrm{ng} / \mathrm{mL}$ or $100 \mathrm{pg} / \mathrm{mL}$, or IFN- $\beta$ (Milteny Biotech, ref. number: $130-107-888$ ) at $10 \mathrm{ng} / \mathrm{mL}$, for $16 \mathrm{~h}$ at $37{ }^{\circ} \mathrm{C}$. Each sample was tested once for each cytokine and dose. Finally, cells were lysed for $20 \mathrm{~min}$ at room temperature, and luciferase levels were measured with the Dual-Luciferase ${ }^{\circledR}$ Reporter 1000 assay system (Promega, ref. number E1980), according to the manufacturer's protocol. Luminescence intensity was measured with a VICTOR-X Multilabel Plate Reader (PerkinElmer Life Sciences, USA). Firefly luciferase activity values were normalized against Renilla luciferase activity values. These values were then normalized against the median induction level for non-neutralizing samples and expressed as a percentage. Samples were considered neutralizing if luciferase induction, normalized against Renilla luciferase activity, was below $15 \%$ of the median values for controls tested the same day.

\section{Research of Antinuclear Antibodies}

An indirect immunofluorescence assay on HEp-2 cells (Kallestad HEp-2 kit, Biorad, ref number 30472) was used for research of antinuclear antibodies (ANA) in patients with auto-Abs neutralizing type I IFNs, with a screening dilution of $1 / 160$.

\section{Statistical Analyses}

To compare clinic characteristics, continuous variables are shown with the median and standard deviation (SD) and dichotomous variables are presented with the number of events and percentages.

Given the small samples size, a Fisher test was used to analyze the effect of dichotomous variables and a Mann-Whitney test for continuous variables.

\section{Results}

\section{Detection of Auto-Abs Neutralizing IFN-a2 and/ or IFN-w}

We first assessed the levels of circulating auto-Abs against IFN- $\alpha 2$ and IFN- $\omega$ using the Gyros technology in 139 patients with critical COVID-19 pneumonia. We found that 107 (77\%) patients with critical COVID-19 have auto-Abs against IFN- $\alpha$ and/or IFN- $\omega$ by Gyros technology. Intermediate titer (between 30 and 100, as previously described [14]) was frequent, as found in $66.9 \%$ (93 of 139) of patients with critical COVID-19 and high levels, above 100, were found in 10.1\% (14 of 139) patients with critical COVID-19.

We then tested the neutralizing activity of all these samples against IFN- $\alpha$ and IFN- $\omega$ in vitro at high concentrations of type I IFNs $(10 \mathrm{ng} / \mathrm{mL})$ and lower concentrations $(100 \mathrm{pg} / \mathrm{mL}$ ) whether they display high titer by Gyros assay or not. We found that $2.9 \%$ (4 of 139) of patients had autoAbs neutralizing $10 \mathrm{ng} / \mathrm{mL}$ of IFN- $\alpha 2$ and/or IFN- $\omega$. Three of these patients had auto-Abs neutralizing high concentrations of IFN- $\alpha 2$ and IFN- $\omega$ and 1 patient had only auto-Abs neutralizing high concentrations of IFN- $\alpha 2$. Moreover, some patients presented auto-Abs neutralizing only $100 \mathrm{pg} / \mathrm{mL}$ of IFN- $\alpha 2$ and/or IFN- $\omega$ but not higher concentrations. We found that $5 \%$ (7 of 139) of patients had auto-Abs neutralizing only lower concentrations of IFN- $\alpha 2$ or IFN- $\omega$. Two of these patients had auto-Abs against only IFN- $\alpha 2$ and 5 patients had auto-Abs against IFN- $\omega$ only.

Lastly, no patients with neutralizing activity against $10 \mathrm{ng} / \mathrm{mL}$ of IFN- $\beta$ were observed in our study. Overall, $7.9 \%$ of the patients displays neutralizing activity against IFN- $\alpha$ and/or IFN- $\omega$.

Only 27\% (3 of 11) of these patients with neutralizing auto-Abs presented high levels of auto-Abs in Gyros assay, other patients having intermediate levels in Gyros assay or even no detectable auto-Abs. Two patients with neutralizing auto-Abs against IFN- $\alpha$ and 3 patients with neutralizing auto-Abs against IFN- $\omega$ had no detectable auto-Abs in Gyros assay (Table 1). Moreover, unlike previous studies, where most samples with high titer of auto-Abs in Gyros assay were neutralizing in vitro [14], 79\% (11 of 14) of patients 
Table 1 Levels of auto-Abs obtained by Gyros in patients with neutralizing activity against type I IFNs

\begin{tabular}{clcc}
\hline & Neutralizing auto-Abs & Gyros anti-IFN- $\alpha$ & Gyros anti-IFN- $\omega$ \\
\hline \multicolumn{2}{c}{ Auto-Abs neutralizing only $10 \mathrm{ng} / \mathrm{ml}$ of type I IFNs } & & \\
Patient 1 & Anti-IFN- $\alpha 2$ and anti IFN- $\omega$ & $367,899^{* *}$ & 25,908 \\
Patient 2 & Anti-IFN- $\alpha 2$ and anti IFN- $\omega$ & $228,684^{* *}$ & $30,122^{*}$ \\
Patient 3 & Anti-IFN- $\alpha 2$ and anti IFN- $\omega$ & $249,683^{* *}$ & $56,4271^{*}$ \\
Patient 4 & Anti-IFN- $\alpha 2$ only & $0,395,918$ & $0,540,107$ \\
Auto-Abs neutralizing & only 100 pg/ml of type I IFNs & & \\
Patient 5 & Anti-IFN- $\alpha 2$ only & $65,5719^{*}$ & $75,3769^{*}$ \\
Patient 6 & Anti-IFN- $\alpha 2$ only & 15,1039 & $69,0513^{*}$ \\
Patient 7 & Anti-IFN- $\omega$ only & $46,03 *$ & $55,9145^{*}$ \\
Patient 8 & Anti-IFN- $\omega$ only & $52,352^{*}$ & $47,1288^{*}$ \\
Patient 9 & Anti-IFN- $\omega$ only & $46,5971^{*}$ & $72,4223^{*}$ \\
Patient 10 & Anti-IFN- $\omega$ only & $86,6252^{*}$ & $74,1435^{*}$ \\
Patient 11 & Anti-IFN- $\omega$ only & $0,426,105$ & $0,333,437$ \\
\hline
\end{tabular}

Levels of auto-Abs against IFN- $\alpha$ and IFN- $\omega$ obtained by Gyros in the 11 patients with neutralizing activity are presented. Results are considered as negative if $<30$, positive with intermediate titer of auto-Abs if $>30$ and $<100(*)$ and positive with high titer of Auto-Abs if $>100(* *)$ with high levels of auto-Abs against IFN- $\alpha 2$ or IFN- $\omega$ in Gyros assay had no neutralizing activity in vitro. Of note, this was mostly observed for IFN- $\omega$, where $100 \%$ of high titers was not neutralizing while $70 \%$ for IFN- $\alpha 2$ (Fig. $1 \mathrm{~A}$ and $\mathrm{B})$.

\section{Detection of Auto-Abs to Type I IFNs by ELISA}

All samples were tested for the presence of anti IFN- $\alpha 2$ autoAbs by a commercially available ELISA kit assay. Interestingly, only $6.5 \%$ (9 of 139) of patients had anti IFN- $\alpha 2$ autoAbs detectable by ELISA whereas 68\% (94 of 139) patients has auto-Abs against IFN- $\alpha 2$ by Gyros technology.

Three patients had low levels of anti IFN- $\alpha 2$ auto-Abs $(<100 \mathrm{ng} / \mathrm{mL})$. These patients had also intermediate titer of anti IFN- $\alpha 2$ auto-Abs in Gyros assays, but no neutralizing activity.

Moreover, six patients had high titer of anti IFN- $\alpha 2$ autoAbs in ELISA (530.7 ng/mL or $>1000 \mathrm{ng} / \mathrm{mL}$ ). In Gyros assay, IFN- $\alpha 2$ auto-Abs were present with high levels in 3 patients, intermediate level in 1 patient and no dectectable in 2 patients (Fig. 2A).

Interestingly, all the 6 patients with high titer auto-Abs in ELISA have a neutralizing activity in vitro against IFN$\alpha 2$ (Fig. 2B). Three of these patients had auto-Abs neutralizing high concentrations of IFN- $\alpha 2$ and IFN- $\omega, 1$ of these patients had auto-Abs neutralizing high concentrations of IFN- $\alpha 2$, and 2 of these patients had auto-Abs neutralizing lower concentrations of IFN- $\alpha 2$. High levels IFN- $\alpha 2$ autoAbs were notably detected in ELISA in the 2 patients with neutralizing activity against IFN- $\alpha 2$ but without detectable auto-Abs in Gyros assay. Presence of high titer of auto-Abs against IFN- $\alpha 2$ in ELISA seems to be better correlated with neutralizing activity of auto-Abs than Gyros technology.

Among the 6 patients with high titer IFN- $\alpha 2$ antibodies detected by ELISA, 3 patients survived. A sample was collected 10 months after COVID-19 pneumonia for 2 of these surviving patients and analyzed by ELISA. Interestingly, high levels of IFN- $\alpha 2$ antibodies remained in these patients. We indeed observed a level of anti IFN- $\alpha 2$ autoAbs that remained $>1000 \mathrm{ng} / \mathrm{mL}$ in one patient and a level that decreased from $530.7 \mathrm{ng} / \mathrm{mL}$ to $239.3 \mathrm{ng} / \mathrm{mL}$ in another patient. These results indicate a persistence of auto-Abs at least 10 months after COVID-19 infection. These patients continue to be followed in hospital, especially in order to see if they develop again a severe COVID-19 pneumonia or other viral infections.

\section{Increased Mortality of Patients with Neutralizing Auto-Abs to Type I IFNs}

We compared the clinical characteristics of patients having neutralizing auto-Abs against type I IFNs with patients without neutralizing auto-Abs (Table 2). Although differences were not significant with the patients without neutralizing auto-Abs, most of patients with neutralizing auto-Abs were men $(82 \%)$. Eighty-two percent of patients with neutralizing auto-Abs was over the age of 65 years, and neutralizing autoAbs was present in $12.5 \%$ of patients with critical COVID19 over the age of 80 years.

In our study, 67\% (93 of 139) of the patients was labeled as having a full engagement status, meaning with no limitation of care. The full engagement status was significantly less frequent in patient with auto-Abs (36\%) than in patients without auto-Abs (70\%). Nevertheless, no differences were 
Fig. 1 A Plot of anti-IFN- $\alpha 2$ auto-Abs levels, as determined by Gyros, against their neutralization capacity at $100 \mathrm{pg} /$ $\mathrm{ml}$. The black vertical line indicates neutralizing levels, with samples being considered neutralizing if luciferase induction, normalized against Renilla luciferase activity, was below $15 \%$ of the median values for controls tested the same day. The horizontal lines represent Gyros auto-Abs levels, with the dark red horizontal line representing high level (>100) and the light red line intermediate level (>30) of Gyros auto-Abs. B Plot of anti-IFN- $\omega$ auto-Abs levels, as determined by Gyros, against their neutralization capacity at $100 \mathrm{pg} / \mathrm{ml}$. The black vertical line indicates neutralizing levels, with samples being considered neutralizing if luciferase induction, normalized against Renilla luciferase activity, was below $15 \%$ of the median values for controls tested the same day. The horizontal lines represent Gyros auto-Abs levels, with the dark red horizontal line representing high level $(>100)$ and the light red line intermediate level (>30) of Gyros auto-Abs
A

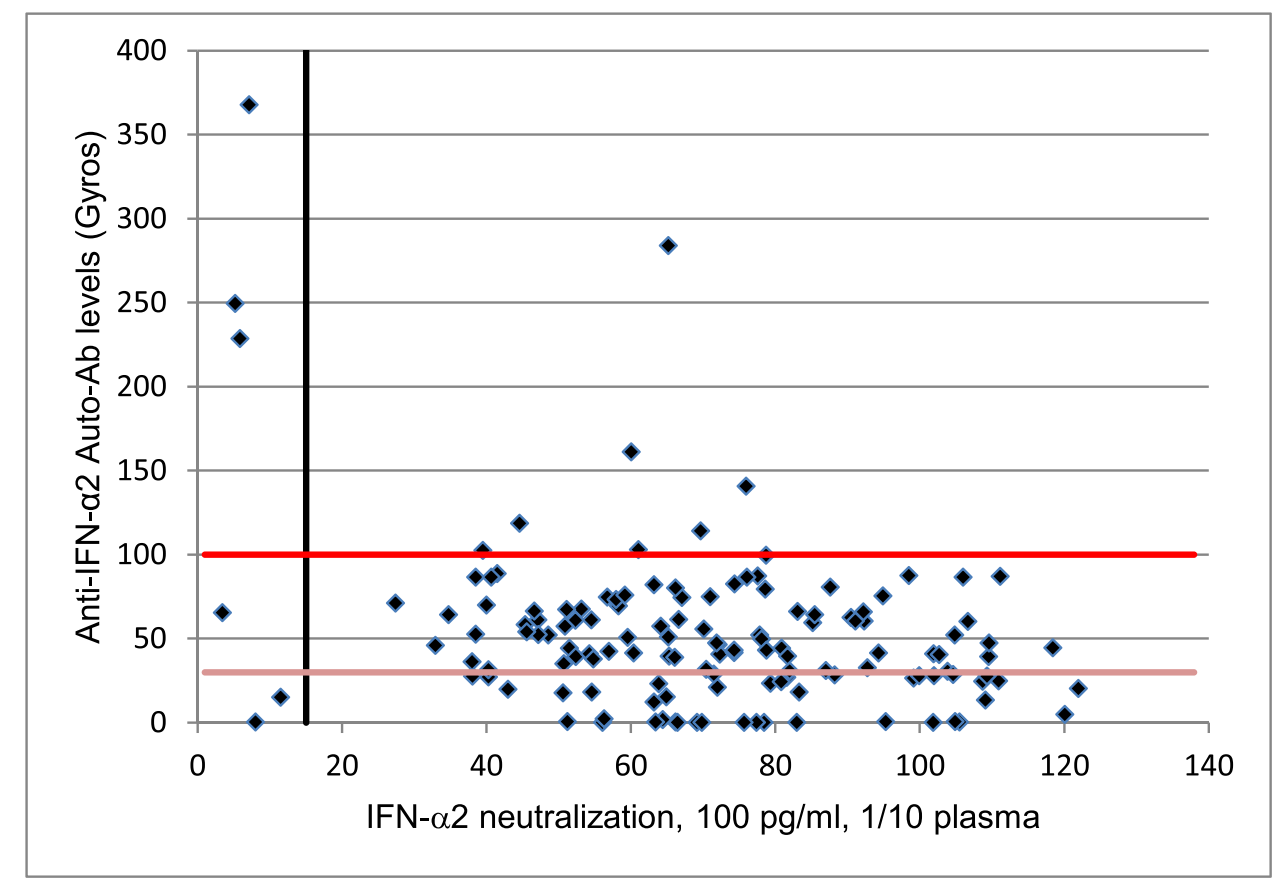

B

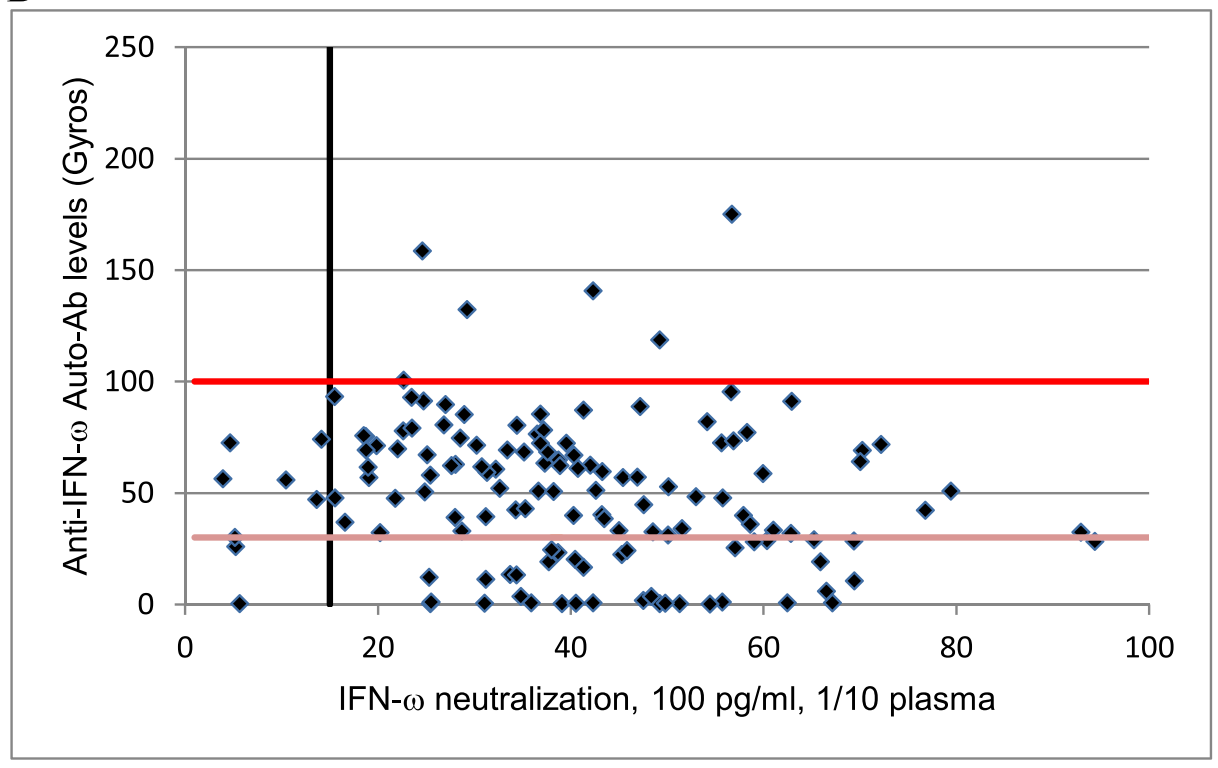

seen between patients with or without auto-Abs for comorbidities and biological characteristics at hospital admission. Moreover, there was no difference in the proportion of patients that were transferred to an ICU between patients with or without auto-Abs.

Finally, it was recently shown that at least $18 \%$ of patients who died of COVID-19 pneumonia had auto-Abs capable of neutralizing $100 \mathrm{pg} / \mathrm{mL}$ type I IFNs in plasma $1 / 10$ [14]. In our study, the mortality was significantly more frequent in patients with neutralizing auto-Abs as
$55 \%$ ( 6 of 11 ) of patients with auto-Abs died versus $18 \%$ (23 of 128) of patients without auto-Abs. Twenty-one percent of critical patients of our cohort who died from COVID-19 pneumonia had auto-Abs capable of neutralizing $100 \mathrm{pg} / \mathrm{mL}$ type I IFNs in plasma 1/10.

We compared clinic characteristics of deceased patients having neutralizing auto-Abs against type I IFNs with deceased patients without neutralizing auto-Abs. Although the deceased patients were usually elderly men, 
Fig. 2 A Plot of anti-IFN- $\alpha 2$ auto-Abs levels, as determined by Gyros, against anti-IFN- $\alpha 2$ auto-Abs levels, as determined by ELISA. The black vertical line represent high level $(>100 \mathrm{ng} / \mathrm{ml})$ of anti-IFN- $\alpha 2$ auto-Abs determined by ELISA. The horizontal lines represent Gyros auto-Abs levels, with the dark red horizontal line representing high level $(>100)$ and the light red line intermediate level (>30) of Gyros auto-Abs. B Plot of anti-IFN- $\alpha 2$ auto-Abs levels, as determined by ELISA, against their neutralization capacity at $100 \mathrm{pg} / \mathrm{ml}$. The black vertical line indicates neutralizing levels, with samples being considered neutralizing if luciferase induction, normalized against Renilla luciferase activity, was below $15 \%$ of the median values for controls tested the same day. The black horizontal line represent high level $(>100 \mathrm{ng} / \mathrm{ml})$ of antiIFN- $\alpha 2$ auto-Abs determined by ELISA

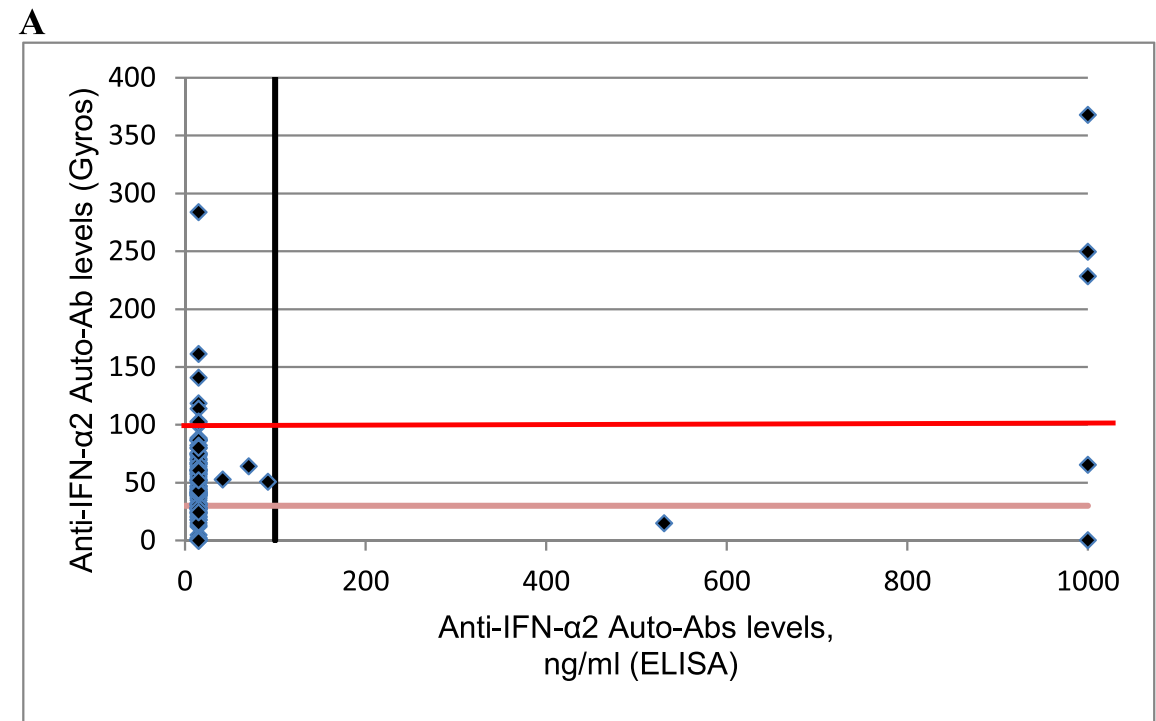

B

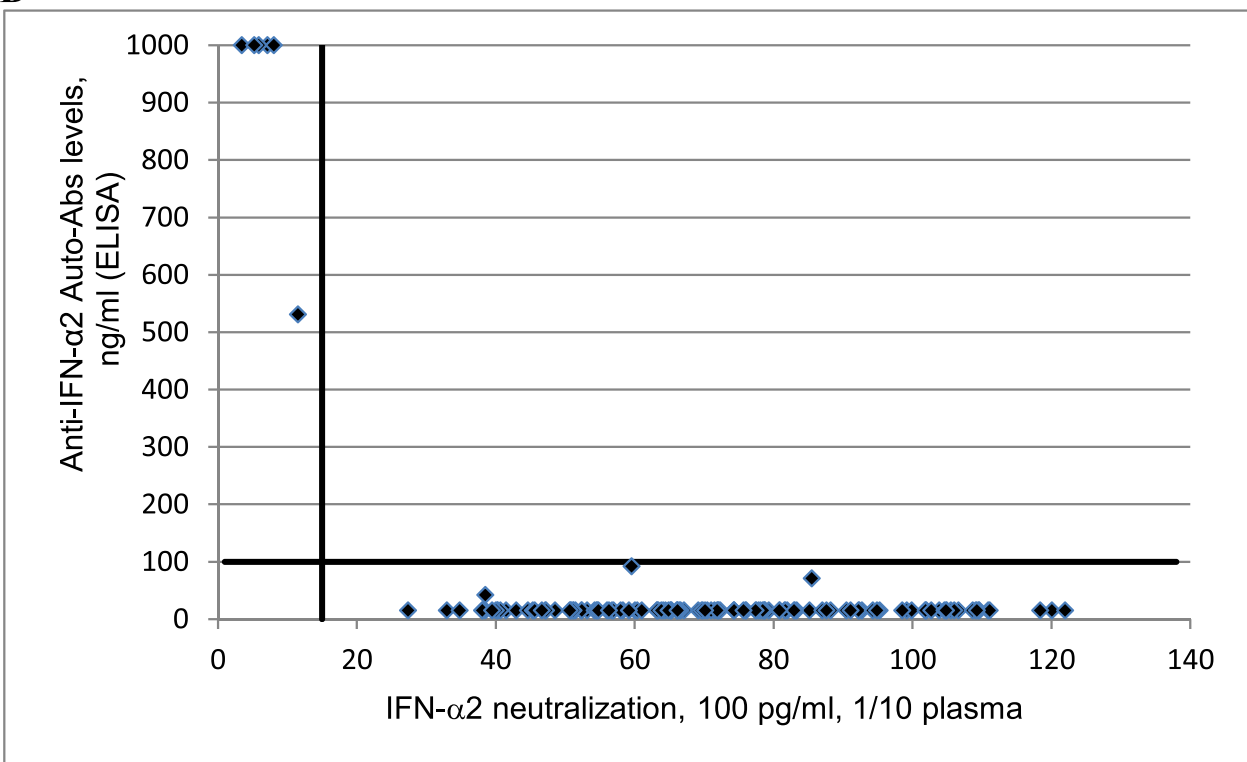

no significant differences were observed between the two groups (Table 3).

\section{Characteristics of Patients with Non-Neutralizing Auto-Abs to Type I IFNs}

Many patients of the cohort had frequently auto-Abs, sometimes with high titer, without detected neutralizing activity. Indeed, $79 \%$ (11 of 14) of patients with high titer of auto-Abs had no apparent neutralizing activity in vitro. We compared characteristics of patients with neutralizing auto-Abs with patients with high titer auto-Abs without neutralizing activity and patients with intermediate titer auto-Abs without neutralizing activity (Table 4). Men and old patients were more frequent in patients with neutralizing Auto-Abs (82\% of male patients, 9 of 11 and $82 \%$ of patients over 65 years old, 9 of 11) than in patients with auto-Abs without neutralizing activity (58\% of male patients, 57 of 98 and $52 \%$ of patients over 65 years old, 51 of 98 ) but the difference was not significant ( $p=0.19$ and $p=0.11$ respectively). Deaths were significantly more frequent in patients with neutralizing antibodies than in patients with intermediate titer auto-Abs without neutralizing activity $(p=0.01)$. Moreover, there were more deaths in patients with neutralizing antibodies than in patients with high titer auto-Abs without neutralizing activity, without the difference being significant $(p=0.18)$. These auto-Abs might be falsely positive or might be able to neutralize even lower amounts of type I IFNs. 
Table 2 Clinical characteristics of patients

Patients with neutralizing auto-Abs at Patients with auto-Abs without $100 \mathrm{pg} / \mathrm{ml}$ type I IFNs (1/10 dilution) neutralizing activity or without antibodies

\begin{tabular}{|c|c|c|c|}
\hline \multicolumn{4}{|l|}{ Demographics } \\
\hline$n$ & 11 & 128 & \\
\hline Age, mean \pm Standard deviation $(S D)$, years & $68.7 \pm 14.9$ & $64 \pm 15.8$ & $p=0.29$ \\
\hline$\geq 65$ years old & $9(82 \%)$ & $65(51 \%)$ & $p=0.06$ \\
\hline Sex (male) & $9(82 \%)$ & $77(60 \%)$ & $p=0.2$ \\
\hline \multicolumn{4}{|l|}{ Clinical features } \\
\hline $\begin{array}{l}\text { Full engagement (patients with no limitation of } \\
\text { care) }\end{array}$ & $4(36 \%)$ & $89(70 \%)$ & $p=0.04$ \\
\hline Diabetes & $3(27 \%)$ & $51(40 \%)$ & $p=0.5$ \\
\hline Obesity & $3(27 \%)$ & $40(31 \%)$ & $p=1$ \\
\hline Hypertension & $4(36 \%)$ & $67(52 \%)$ & $p=0.4$ \\
\hline $\begin{array}{l}\text { History of cardiovascular disease, stroke, peripheral } \\
\text { artery disease, heart failure }\end{array}$ & $3(27 \%)$ & $27(21 \%)$ & $p=0.7$ \\
\hline $\begin{array}{l}\text { History of chronic obstructive pulmonary disease, } \\
\text { asthma, emphysema, fibrosis }\end{array}$ & $1(9 \%)$ & $22(17 \%)$ & $p=0.69$ \\
\hline Solid organ transplantation & $1(9 \%)$ & $0(0 \%)$ & $p=0.08$ \\
\hline HIV & $0(0 \%)$ & $2(1,6 \%)$ & $p=1$ \\
\hline $\begin{array}{l}\text { Immunosuppressant drugs and/or long-term oral } \\
\text { corticosteroids }\end{array}$ & $2(18 \%)$ & $10(9 \%)$ & $p=0.24$ \\
\hline Malignancy (active) & $2(18 \%)$ & $8(6 \%)$ & $p=0.18$ \\
\hline \multicolumn{4}{|l|}{ Biological characteristics at hospital admission } \\
\hline $\mathrm{C}$ protein reactive, mean $\pm S D, \mathrm{mg} / \mathrm{L}$ & $155 \pm 89$ & $124 \pm 90$ & $p=0.2$ \\
\hline Lymphocyte count, mean $\pm S D, / \mu \mathrm{L}$ & $923 \pm 269$ & $1196 \pm 1044$ & $p=0.3$ \\
\hline Creatinine mean $\pm S D, \mu \mathrm{mol} / \mathrm{L}$ & $273 \pm 434$ & $84 \pm 34$ & $p=0.21$ \\
\hline \multicolumn{4}{|l|}{ Clinical outcomes } \\
\hline Intubed & $1(9 \%)$ & $21(16 \%)$ & $p=1$ \\
\hline Death & $6(55 \%)$ & $23(18 \%)$ & $p=0.01$ \\
\hline
\end{tabular}

Data are presented as a number (percentage), unless otherwise noted. A Fisher test was used to analyze the effect of dichotomous variables and a Mann-Whitney test for continuous variables. Significant values are noted in italics

\section{Discussion}

We assessed the prevalence of auto-Abs against type I IFNs in 139 patients hospitalized for critical COVID-19 pneumonia in medicine departments dedicated to treat COVID-19 patients.

As many as $77 \%$ of patients with critical COVID-19 have auto-Abs against IFN- $\alpha$ and/or IFN- $\omega$ by Gyros technology, mainly with intermediate titer and less frequently with high titer. These results are much higher than those previously described as Bastard et al. described high or intermediate levels of IgG auto-Abs against IFN- $\alpha 2$ and/or IFN- $\omega$ in about $20 \%$ of patients with critical COVID-19 [14]. Our high proportion of intermediate titers could be explained by calibration issues of the Gyros. This nevertheless does not seem to affect the high titers, which remain the most relevant.

However, $79 \%$ of our patients with high levels of autoAbs had no neutralizing activity. We found circulating
auto-Abs that neutralized $100 \mathrm{pg} / \mathrm{mL}$ IFN- $\alpha 2$ and/or IFN- $\omega$ in plasma $1 / 10$ in only $7.9 \%$ of our patients.

These results may reflect a lack of specificity of Gyros technology, especially for auto-Abs against IFN- $\omega$ and for intermediate titer of auto-Abs. Alternatively, there may be insufficient sensitivity of neutralization assays. A third possible explanation is that these auto-Abs may be specific for other type I IFN epitopes, the recognition of which would not interfere with type I IFN binding to its receptor.

We also evaluated a commercially available ELISA kit in our laboratory for detection of IFN- $\alpha 2$ auto-Abs. We did not search anti IFN- $\alpha 2$ auto-Abs by ELISA in general population. Nevertheless, according to manufacturer's results, in a panel of 57 serum samples from randomly selected apparently healthy donors and patients suffering from various diseases, anti-IFN $\alpha 2$ levels ranged between 0 and $120.5 \mathrm{ng} /$ $\mathrm{mL}$ (mean:17.4 ng/mL; SD: $26.7 \mathrm{ng} / \mathrm{mL}$ ). Moreover, this commercial ELISA was recently evaluated [9]; a cut off of 
Table 3 Clinical characteristics of deceased patients

Deceased patients with Deceased patients with auto-Abs without $p$ values neutralizing auto-Abs neutralizing activity or without antibodies

\begin{tabular}{|c|c|c|c|}
\hline \multicolumn{4}{|l|}{ Demographics } \\
\hline$n$ & 6 & 23 & \\
\hline Age, mean \pm standard deviation $(S D)$, years & $74.5 \pm 12.6$ & $75.3 \pm 11.3$ & $p=0.9$ \\
\hline$\geq 65$ years old & $5(83 \%)$ & $21(87 \%)$ & $p=1$ \\
\hline Sex (male) & $4(67 \%)$ & $15(65 \%)$ & $p=1$ \\
\hline \multicolumn{4}{|l|}{ Clinical features } \\
\hline Full engagement (patients with no limitation of care) & $1(17 \%)$ & $6(26 \%)$ & $p=1$ \\
\hline Diabetes & $2(33 \%)$ & $9(39 \%)$ & $p=1$ \\
\hline Obesity & $2(33 \%)$ & $5(22 \%)$ & $p=0.6$ \\
\hline Hypertension & $3(50 \%)$ & $15(65 \%)$ & $p=0.6$ \\
\hline $\begin{array}{l}\text { History of cardiovascular disease, stroke, peripheral artery } \\
\text { disease, heart failure }\end{array}$ & $1(17 \%)$ & $8(35 \%)$ & $p=0.6$ \\
\hline $\begin{array}{l}\text { History of chronic obstructive pulmonary disease, asthma, } \\
\text { emphysema, fibrosis }\end{array}$ & $0(0 \%)$ & $4(17 \%)$ & $p=0.5$ \\
\hline Solid organ transplantation & $1(17 \%)$ & $0(0 \%)$ & $p=0.2$ \\
\hline $\begin{array}{l}\text { Immunosuppressant drugs and/or long-term oral corticos- } \\
\text { teroids }\end{array}$ & $2(33 \%)$ & $2(9 \%)$ & $p=0.2$ \\
\hline Malignancy (active) & $2(33 \%)$ & $2(9 \%)$ & $p=0.2$ \\
\hline \multicolumn{4}{|l|}{ Clinical outcomes } \\
\hline Intubed & $1(17 \%)$ & $4(17 \%)$ & $p=1$ \\
\hline
\end{tabular}

Data are presented as a number (percentage), unless otherwise noted. A Fisher test was used to analyze the effect of dichotomous variables and a Mann-Whitney test for continuous variables

Table 4 Clinical characteristics of with auto-Abs to type I IFNs detectable but non neutralizing

\begin{tabular}{llll}
\hline & $\begin{array}{l}\text { Patients with intermediate titer of antibod- } \\
\text { ies against type I IFNS without neutralizing } \\
\text { activity }\end{array}$ & $\begin{array}{l}\text { Patients with high titer of antibodies } \\
\text { against type I IFNS without neutralizing } \\
\text { activity }\end{array}$ & $\begin{array}{l}\text { Patients with neutralizing } \\
\text { auto-Abs against type I } \\
\text { IFNs }\end{array}$ \\
\hline$n$ & 87 & 11 & 11 \\
$\begin{array}{l}\text { Age, mean } \pm \text { Standard } \\
\text { deviation }(S D),\end{array}$ & $64.9 \pm 16.2$ & $60.5 \pm 16.1$ & $68.7 \pm 14.9$ \\
$\begin{array}{l}\text { years } \\
\geq 65 \text { years old }\end{array}$ & $46(53 \%)$ & $5(45 \%)$ & $9(82 \%)$ \\
Men & $51(59 \%)$ & $6(55 \%)$ & $9(82 \%)$ \\
Death & $15(17 \%)$ & $2(18 \%)$ & $6(55 \%)$ \\
\hline
\end{tabular}

Data are presented as a number (percentage), unless otherwise noted. A Fisher test was used to analyze the effect of dichotomous variables and a Mann-Whitney test for continuous variables

$34 \mathrm{ng} / \mathrm{mL}$ was established and results $>100 \mathrm{ng} / \mathrm{mL}$ were considered as high. Three of our patients had anti IFN- $\alpha 2$ auto-Abs levels $<100 \mathrm{ng} / \mathrm{mL}$, which were considered as low, and also presented no neutralizing activity in vitro against IFN- $\alpha$. Moreover, in our study, 6 patients had high titer of anti IFN- $\alpha 2$ auto-Abs in ELISA and presented all a neutralizing activity in vitro against IFN- $\alpha 2$. Goncalves et al. [9] showed similar results and determined a cut-off of $1000 \mathrm{ng} /$ $\mathrm{mL}$ correlated with neutralization assays. In their study, ability of auto-Abs to neutralize only high concentrations of IFN- $\alpha 2(10 \mathrm{ng} / \mathrm{mL})$ was investigated. In our study, we tested the neutralizing activity of all these samples against IFNs in vitro at high concentrations and lower concentrations. In one of our patient, a concentration of $530.7 \mathrm{ng} / \mathrm{mL}$ was shown to be correlated with ability of auto-Abs to neutralize $100 \mathrm{pg} / \mathrm{mL}$ IFN- $\alpha 2$ in plasma $1 / 10$. These results have to be confirmed in more samples, and it is also necessary to determinate cut off correlated with neutralizing activity against low concentration of IFN- $\alpha 2$. High levels IFN- $\alpha 2$ auto-Abs were notably detected in ELISA in 2 patients with neutralizing activity against IFN- $\alpha 2$ but without detectable auto-Abs in Gyros assay. The difference between Gyros technology 
and Invitrogen ELISA could be explained by the nature of the conjugate, secondary antibody, goat anti-human IgG, and HRP-conjugated human IFN- $\alpha 2$ protein respectively, probably leading to a better detection of auto antibodies with ELISA. Overall, high titer auto-Abs against IFN- $\alpha 2$ in ELISA seems to be better correlated with neutralizing activity of auto-Abs than Gyros.

The proportion of patients with type I IFNs neutralizing auto-Abs is lower than those obtained in previous studies as it was described auto-Abs that neutralized $100 \mathrm{pg} / \mathrm{mL}$ IFN- $\alpha 2$ and/or IFN- $\omega$ in plasma $1 / 10$ in $13.6 \%$ of the critical patients [14]. However, our cohort included only patients that were at the first day of hospitalization in medicine departments dedicated to treat COVID-19 patients, with an oxygen support $\geq 6 \mathrm{~L} / \mathrm{min}$ with oxygen mask, for more than $6 \mathrm{~h}$. It was indeed initially constituted in order to assess associations between treatments and outcomes like need of ventilation mechanic and mortality [16]. Overall, severity of patients studied here was potentially lower than that of patients hospitalized in intensive care units [5, 6, 9-11, 14].

Previous studies showed that patients with neutralizing auto-Abs against type I IFNs were mostly men (94\%) and that half were older than 65 years [5]. Moreover, it was recently shown that proportion of patients with critical COVID-19 having neutralizing auto-Abs increased with age [14]. In our study, although differences were not significant with regard to the patients without neutralizing auto-Abs, most of patients (82\%) with neutralizing auto-Abs were men and over the age of 65 years. The full engagement status was significantly less frequent in patient with auto-Abs than in patients without auto-Abs but like other studies [7, 9], there was no difference for comorbidities. Unlike to study by Troya et al. [7], where a significant correlation between the presence of auto-Abs neutralizing type I IFNs, raised levels of C-protein reactive, and low lymphocytes counts was observed, in our study, no difference was seen for these biological characteristics. It is nevertheless important to note that we compare biological characteristics obtained at hospital admission, and not maximum levels of C-protein reactive and minimum levels of lymphocytes count.

Neutralizing antibodies against type I INFs was described in almost all of patients with auto immune polyendocrinopathy syndrome type I [18-20] but also in patients with thymoma, myasthenia gravis [21] and systemic lupus erythematosus [22-24]. In our cohort, these autoimmune diseases were not described in patients with neutralizing auto-Abs, although 2 of 11 (18\%) patients with neutralizing Auto-Abs against type I IFNs had a history of psoriasis. Research of antinuclear antibodies (ANA) did not reveal high titer of ANA in the 6 patients that were analyzed.

Like in a previous study [14], the presence of neutralizing auto-Abs is associated with a more frequent mortality. Up to $21 \%$ of patients who died of COVID-19 pneumonia in our study had auto-Abs capable of neutralizing $100 \mathrm{pg} / \mathrm{mL}$ type I IFNs in plasma 1/10. Deceased patients with autoAbs did not present overt clinical differences with deceased patients without auto-Abs. These results confirm importance of the IFN-I pathway in the defense against SARS-CoV-2 infection.

Overall, the detection of neutralizing Auto-Abs against type I IFNs is therefore important due to clinical applications, notably therapeutics. All COVID-19 patients should be screened for these autoantibodies in order to predict which patients infected by SARS-CoV-2 are at higher risk of life-threatening COVID-19. Moreover, early identification of COVID-19 patients with auto-Abs should prompt early treatment and preventive management.

As high titers auto-Abs against IFN-2 in ELISA are well correlated with neutralizing activity of auto-Abs, this commercial ELISA should be used to detect easily, in routine clinical practice, neutralizing anti IFN-2 auto-Abs. Nevertheless, to our knowledge, no commercial ELISA exists to detect anti IFN- auto-Abs. It would be necessary to complete detection of anti IFN-2 auto-Abs with a functional evaluation of neutralizing anti IFN- auto-Abs, notably if low IFN-2 auto-Abs levels or no IFN-2 auto-Abs are detected.

Lastly, our study describes persistence of neutralizing Auto-Abs almost 1 year after COVID-19 infection in two patients. Risk associated with this persistence is not known to date but must be explored, especially given the potential impact of these auto-Abs on the severity of other viral diseases, as described for adverse reactions following yellowfever vaccination [25].

Acknowledgements We thank the patients and their families for placing their trust in us. We warmly thank the members of the Medical Biology Department of Robert Ballanger Hospital and the members of both branches of the Laboratory of Human Genetics of Infectious Diseases. We warmly thank Karim Dorgham (Center for immunology and microbial infections, CIMI-Paris, INSERM U1135) for his advice about ELISA.

Author Contribution Authors have participated in the conception and design, lab experiments, collection, and analysis and interpretation of the data; drafting the article and revising it critically for important intellectual content; and approval of the final version. ACG: Conception and design, experiments in Robert Ballanger Hospital, analysis and interpretation of the data, drafting the article, revising it critically for important intellectual content, and approval of the final version. PB: Performed the experiments in Imagine Institute, analysis and interpretation of the data, drafting the article, revising it critically for important intellectual content, and approval of the final version. AS: Performed the experiments in Robert Ballanger Hospital. AG and JR: Performed the experiments in Imagine Institute. EJ and AC: Analysis and interpretation of the data. JLC: Revising it critically for important intellectual content and approval of the final version. BR: Conception and design, collection, analysis and interpretation of the data, revising it critically for important intellectual content, and approval of the final version.

Funding The Laboratory of Human Genetics of Infectious Diseases is supported by the Howard Hughes Medical Institute, the Rockefeller 
University, the St. Giles Foundation, the National Institutes of Health (NIH) (R01AI088364), the National Center for Advancing Translational Sciences (NCATS), NIH Clinical and Translational Science Award (CTSA) program (UL1 TR001866), a Fast Grant from Emergent Ventures, Mercatus Center at George Mason University, the Yale Center for Mendelian Genomics and the GSP Coordinating Center funded by the National Human Genome Research Institute (NHGRI) (UM1HG006504 and U24HG008956), the Yale High Performance Computing Center (S10OD018521), the Fisher Center for Alzheimer's Research Foundation, the Meyer Foundation, the JPB Foundation, the French National Research Agency (ANR) under the "Investments for the Future" program (ANR-10-IAHU-01), the Integrative Biology of Emerging Infectious Diseases Laboratory of Excellence (ANR-10LABX-62-IBEID), the French Foundation for Medical Research (FRM) (EQU201903007798), the FRM and ANR GENCOVID project (ANR20-COVI-0003), ANRS Nord-Sud (ANRS-COV05), ANR GENVIR (ANR-20-CE93-003) and ANR AABIFNCOV (ANR-20-CO11-0001) projects, the European Union's Horizon 2020 research and innovation program under grant agreement no. 824110 (EASI-genomics), the Square Foundation, Grandir-Fonds de solidarité pour l'enfance, the Fondation du Souffle, the SCOR Corporate Foundation for Science, Institut National de la Santé et de la Recherche Médicale (INSERM), and the University of Paris. PB was supported by the French Foundation for Medical Research (FRM, EA20170638020). PB and JR were supported by the MD-PhD program of the Imagine Institute (with the support of the Fondation Bettencourt-Schueller).

Data Availability Clinical data files are stored at Robert Ballanger Hospital. It may be shared if needed.

\section{Declarations}

Ethics Approval This study was approved by a research ethics committee and was registered on clinicaltrials.gov (NCT04366206).

Consent to Participate Informed consent was obtained from the patients included in this study.

Consent for Publication This consent was obtained with consent to participate.

Competing Interests JLC reports 2 patents pending, application number 63/055,155 filed July 22, 2020 and application number 63/141,669 filed January 26, 2021 pending.

\section{References}

1. Levin AT, Hanage WP, Owusu-Boaitey N, Cochran KB, Walsh SP, Meyerowitz-Katz G. Assessing the age specificity of infection fatality rates for COVID-19: systematic review, meta-analysis, and public policy implications. Eur J Epidemiol. 2020;35(12):112338. https://doi.org/10.1007/s10654-020-00698-1.

2. O'Driscoll M, Ribeiro Dos Santos G, Wang L, Cummings DAT, Azman AS, Paireau J, Fontanet A, Cauchemez S, Salje H. Age-specific mortality and immunity patterns of SARSCoV-2. Nature. 2021;590(7844):140-5. https://doi.org/10.1038/ s41586-020-2918-0.

3. Zhang Q, Bastard P, Liu Z, Le Pen J, Moncada-Velez M, Chen J, Ogishi M, Sabli IKD, Hodeib S, Korol C, Rosain J, Bilguvar K, Ye J, Bolze A, Bigio B, Yang R, Arias AA, Zhou Q, Zhang Y, Onodi F, Korniotis S, Karpf L, Philippot Q, Chbihi M, Bonnet-Madin L, Dorgham K, Smith N, Schneider WM, Razooky
BS, Hoffmann H-H, Michailidis E, Moens L, Han JE, Lorenzo L, Bizien L, Meade P, Neehus A-L, Ugurbil AC, Corneau A, Kerner G, Zhang P, Rapaport F, Seeleuthner Y, Manry J, Masson C, Schmitt Y, Schlüter A, Le Voyer T, Khan T, Li J, Fellay J, Roussel L, Shahrooei M, Alosaimi MF, Mansouri D, Al-Saud H, Al-Mulla F, Almourfi F, Al-Muhsen, S. Z.; Alsohime, F.; Al Turki, S.; Hasanato, R.; van de Beek, D.; Biondi, A.; Bettini, L. R.; D’Angio', M.; Bonfanti, P.; Imberti, L.; Sottini, A.; Paghera, S.; Quiros-Roldan, E.; Rossi, C.; Oler, A. J.; Tompkins, M. F.; Alba, C.; Vandernoot, I.; Goffard, J.-C.; Smits, G.; Migeotte, I.; Haerynck, F.; Soler-Palacin, P.; Martin-Nalda, A.; Colobran, R.; Morange, P.-E.; Keles, S.; Çölkesen, F.; Ozcelik, T.; Yasar, K. K.; Senoglu, S.; Karabela, Ş. N.; Rodríguez-Gallego, C.; Novelli, G.; Hraiech, S.; Tandjaoui-Lambiotte, Y.; Duval, X.; Laouénan, C.; COVID-STORM Clinicians $\uparrow$; COVID Clinicians $\dagger ;$ Imagine COVID Group †; French COVID Cohort Study Group †; CoVContact Cohort†; Amsterdam UMC Covid-19 Biobank †; COVID Human Genetic Effort $†$; NIAID-USUHS/TAGC COVID Immunity Group $\dagger$; Snow, A. L.; Dalgard, C. L.; Milner, J. D.; Vinh, D. C.; Mogensen, T. H.; Marr, N.; Spaan, A. N.; Boisson, B.; Boisson-Dupuis, S.; Bustamante, J.; Puel, A.; Ciancanelli, M. J.; Meyts, I.; Maniatis, T.; Soumelis, V.; Amara, A.; Nussenzweig, M.; García-Sastre, A.; Krammer, F.; Pujol, A.; Duffy, D.; Lifton, R. P.; Zhang, S.-Y.; Gorochov, G.; Béziat, V.; Jouanguy, E.; Sancho-Shimizu, V.; Rice, C. M.; Abel, L.; Notarangelo, L. D.; Cobat, A.; Su, H. C.; Casanova, J.-L. Inborn errors of type I IFN immunity in patients with life-threatening COVID-19. Science 2020; 370(6515), eabd4570. https://doi.org/10.1126/science. abd4570.

4. Asano, T.; Boisson, B.; Onodi, F.; Matuozzo, D.; MoncadaVelez, M.; Maglorius Renkilaraj, M. R. L.; Zhang, P.; Meertens, L.; Bolze, A.; Materna, M.; Korniotis, S.; Gervais, A.; Talouarn, E.; Bigio, B.; Seeleuthner, Y.; Bilguvar, K.; Zhang, Y.; Neehus, A.-L.; Ogishi, M.; Pelham, S. J.; Le Voyer, T.; Rosain, J.; Philippot, Q.; Soler-Palacín, P.; Colobran, R.; Martin-Nalda, A.; Rivière, J. G.; Tandjaoui-Lambiotte, Y.; Chaïbi, K.; Shahrooei, M.; Darazam, I. A.; Olyaei, N. A.; Mansouri, D.; Hatipoğlu, N.; Palabiyik, F.; Ozcelik, T.; Novelli, G.; Novelli, A.; Casari, G.; Aiuti, A.; Carrera, P.; Bondesan, S.; Barzaghi, F.; Rovere-Querini, P.; Tresoldi, C.; Franco, J. L.; Rojas, J.; Reyes, L. F.; Bustos, I. G.; Arias, A. A.; Morelle, G.; Christèle, K.; Troya, J.; Planas-Serra, L.; Schlüter, A.; Gut, M.; Pujol, A.; Allende, L. M.; RodriguezGallego, C.; Flores, C.; Cabrera-Marante, O.; Pleguezuelo, D. E.; de Diego, R. P.; Keles, S.; Aytekin, G.; Akcan, O. M.; Bryceson, Y. T.; Bergman, P.; Brodin, P.; Smole, D.; Smith, C. I. E.; Norlin, A.-C.; Campbell, T. M.; Covill, L. E.; Hammarström, L.; PanHammarström, Q.; Abolhassani, H.; Mane, S.; Marr, N.; Ata, M.; Al Ali, F.; Khan, T.; Spaan, A. N.; Dalgard, C. L.; Bonfanti, P.; Biondi, A.; Tubiana, S.; Burdet, C.; Nussbaum, R.; Kahn-Kirby, A.; Snow, A. L.; COVID Human Genetic Effort $\uparrow$; COVIDSTORM Clinicians $\dagger$; COVID Clinicians $\uparrow$; Imagine COVID Group $\dagger$; French COVID Cohort Study Group $†$; CoV-Contact Cohort $\dagger$; Amsterdam UMC Covid-19; Biobank $\dagger$; NIAID-USUHS COVID Study Group †; Bustamante, J.; Puel, A.; Boisson-Dupuis, S.; Zhang, S.-Y.; Béziat, V.; Lifton, R. P.; Bastard, P.; Notarangelo, L. D.; Abel, L.; Su, H. C.; Jouanguy, E.; Amara, A.; Soumelis, V.; Cobat, A.; Zhang, Q.; Casanova, J.-L. X-linked recessive TLR7 deficiency in $\sim 1 \%$ of men under 60 years old with life-threatening COVID-19. Sci. Immunol. 2021, 6 (62), eabl4348. https://doi.org/ 10.1126/sciimmunol.abl4348.

5. Bastard, P.; Rosen, L. B.; Zhang, Q.; Michailidis, E.; Hoffmann, H.-H.; Zhang, Y.; Dorgham, K.; Philippot, Q.; Rosain, J.; Béziat, V.; Manry, J.; Shaw, E.; Haljasmägi, L.; Peterson, P.; Lorenzo, L.; Bizien, L.; Trouillet-Assant, S.; Dobbs, K.; de Jesus, A. A.; Belot, A.; Kallaste, A.; Catherinot, E.; Tandjaoui-Lambiotte, Y.; Le Pen, J.; Kerner, G.; Bigio, B.; Seeleuthner, Y.; Yang, R.; Bolze, A.; 
Spaan, A. N.; Delmonte, O. M.; Abers, M. S.; Aiuti, A.; Casari, G.; Lampasona, V.; Piemonti, L.; Ciceri, F.; Bilguvar, K.; Lifton, R. P.; Vasse, M.; Smadja, D. M.; Migaud, M.; Hadjadj, J.; Terrier, B.; Duffy, D.; Quintana-Murci, L.; van de Beek, D.; Roussel, L.; Vinh, D. C.; Tangye, S. G.; Haerynck, F.; Dalmau, D.; MartinezPicado, J.; Brodin, P.; Nussenzweig, M. C.; Boisson-Dupuis, S.; Rodríguez-Gallego, C.; Vogt, G.; Mogensen, T. H.; Oler, A. J.; Gu, J.; Burbelo, P. D.; Cohen, J. I.; Biondi, A.; Bettini, L. R.; D’Angio, M.; Bonfanti, P.; Rossignol, P.; Mayaux, J.; RieuxLaucat, F.; Husebye, E. S.; Fusco, F.; Ursini, M. V.; Imberti, L.; Sottini, A.; Paghera, S.; Quiros-Roldan, E.; Rossi, C.; Castagnoli, R.; Montagna, D.; Licari, A.; Marseglia, G. L.; Duval, X.; Ghosn, J.; HGID Lab§; NIAID-USUHS Immune Response to COVID Group§; COVID Clinicians§; COVID-STORM Clinicians§; Imagine COVID Group\$; French COVID Cohort Study Group\$; The Milieu Intérieur Consortium§; CoV-Contact Cohort§; Amsterdam UMC Covid-19 Biobank§; COVID Human Genetic Effort§; Tsang, J. S.; Goldbach-Mansky, R.; Kisand, K.; Lionakis, M. S.; Puel, A.; Zhang, S.-Y.; Holland, S. M.; Gorochov, G.; Jouanguy, E.; Rice, C. M.; Cobat, A.; Notarangelo, L. D.; Abel, L.; Su, H. C.; Casanova, J.-L. Autoantibodies against type I IFNs in patients with life-threatening COVID-19. Science 2020, 370 (6515), eabd4585. https://doi.org/10.1126/science.abd4585.

6. Koning, R.; Bastard, P.; Casanova, J.-L.; Brouwer, M. C.; van de Beek, D.; with the Amsterdam U.M.C. COVID-19 Biobank Investigators; van Agtmael, M.; Algera, A. G.; Appelman, B.; van Baarle, F.; Bax, D.; Beudel, M.; Bogaard, H. J.; Bomers, M.; Bonta, P.; Bos, L.; Botta, M.; de Brabander, J.; Bree, G.; de Bruin, S.; Bugiani, M.; Bulle, E.; Chekrouni, N.; Chouchane, O.; Cloherty, A.; Dongelmans, D. A.; Dujardin, R. W. G.; Elbers, P.; Fleuren, L.; Geerlings, S.; Geijtenbeek, T.; Girbes, A.; Goorhuis, B.; Grobusch, M. P.; Hafkamp, F.; Hagens, L.; Hamann, J.; Harris, V.; Hemke, R.; Hermans, S. M.; Heunks, L.; Hollmann, M.; Horn, J.; Hovius, J. W.; de Jong, M. D.; Koning, R.; Lim, E. H. T.; van Mourik, N.; Nellen, J.; Nossent, E. J.; Olie, S.; Paulus, F.; Peters, E.; van der Poll, T.; Preckel, B.; Prins, J. M.; Raasveld, J.; Reijnders, T.; Schinkel, M.; Schultz, M. J.; Schuurmans, A.; Schuurmans, J.; Sigaloff, K.; Slim, M. A.; Smit, M.; Stijnis, C. S.; Stilma, W.; Teunissen, C.; Thoral, P.; Tsonas, A. M.; van der Valk, M.; Veelo, D.; de Vries, H.; Vught, L. A.; van Vugt, M.; Wouters, D.; Zwinderman, A. H.; Brouwer, M. C.; Wiersinga, W. J.; Vlaar, A. P. J.; van de Beek, D. Autoantibodies against type I interferons are associated with multi-organ failure in COVID-19 patients. Intensive Care Med. 2021, 47 (6), 704-706. https://doi. org/10.1007/s00134-021-06392-4.

7. Troya J, Bastard P, Planas-Serra L, Ryan P, Ruiz M, de Carranza M, Torres J, Martínez A, Abel L, Casanova J-L, Pujol A. Neutralizing autoantibodies to type I IFNs in $>10 \%$ of patients with severe COVID-19 pneumonia hospitalized in Madrid, Spain. J Clin Immunol. 2021;41(5):914-22. https://doi.org/10.1007/ s10875-021-01036-0.

8. Vazquez SE, Bastard P, Kelly K, Gervais A, Norris PJ, Dumont LJ, Casanova J-L, Anderson MS, DeRisi JL. Neutralizing autoantibodies to type I interferons in COVID-19 convalescent donor plasma. J Clin Immunol. 2021;41(6):1169-71. https://doi.org/10. 1007/s10875-021-01060-0.

9. Goncalves, D.; Mezidi, M.; Bastard, P.; Perret, M.; Saker, K.; Fabien, N.; Pescarmona, R.; Lombard, C.; Walzer, T.; Casanova, J.; Belot, A.; Richard, J.; Trouillet-Assant, S. Antibodies against type I interferon: detection and association with severe clinical outcome in COVID-19 patients. Clin. Transl. Immunol. 2021, 10 (8). https://doi.org/10.1002/cti2.1327.

10. Wang, E. Y.; Mao, T.; Klein, J.; Dai, Y.; Huck, J. D.; Liu, F.; Zheng, N. S.; Zhou, T.; Israelow, B.; Wong, P.; Lucas, C.; Silva, J.; Oh, J. E.; Song, E.; Perotti, E. S.; Fischer, S.; Campbell, M.; Fournier, J. B.; Wyllie, A. L.; Vogels, C. B. F.; Ott, I. M.;
Kalinich, C. C.; Petrone, M. E.; Watkins, A. E.; Yale IMPACT Team; Cruz, C. D.; Farhadian, S. F.; Schulz, W. L.; Grubaugh, N. D.; Ko, A. I.; Iwasaki, A.; Ring, A. M. Diverse functional autoantibodies in patients with COVID-19; preprint; Infectious Diseases (except HIV/AIDS), 2020. https://doi.org/10.1101/2020. 12.10.20247205.

11. van der Wijst, M. G. P.; Vazquez, S. E.; Hartoularos, G. C.; Bastard, P.; Grant, T.; Bueno, R.; Lee, D. S.; Greenland, J. R.; Sun, Y.; Perez, R.; Ogorodnikov, A.; Ward, A.; Mann, S. A.; Lynch, K. L.; Yun, C.; Havlir, D. V.; Chamie, G.; Marquez, C.; Greenhouse, B.; Lionakis, M. S.; Norris, P. J.; Dumont, L. J.; Kelly, K.; Zhang, P.; Zhang, Q.; Gervais, A.; Le Voyer, T.; Whatley, A.; Si, Y.; Byrne, A.; Combes, A. J.; Rao, A. A.; Song, Y. S.; Fragiadakis, G. K.; Kangelaris, K.; Calfee, C. S.; Erle, D. J.; Hendrickson, C.; Krummel, M. F.; Woodruff, P. G.; Langelier, C. R.; Casanova, J.-L.; Derisi, J. L.; Anderson, M. S.; Ye, C. J.; on behalf of the UCSF COMET consortium. Type I interferon autoantibodies are associated with systemic immune alterations in patients with COVID19. Sci. Transl. Med. 2021, eabh2624. https://doi.org/10.1126/scitr anslmed.abh2624.

12. Lopez J, Mommert M, Mouton W, Pizzorno A, Brengel-Pesce K, Mezidi M, Villard M, Lina B, Richard J-C, Fassier J-B, Cheynet V, Padey B, Duliere V, Julien T, Paul S, Bastard P, Belot A, Bal A, Casanova J-L, Rosa-Calatrava M, Morfin F, Walzer T, TrouilletAssant S. Early nasal type I IFN immunity against SARS-CoV-2 is compromised in patients with autoantibodies against type I IFNs. J Exp Med. 2021;218(10): e20211211. https://doi.org/10.1084/ jem.20211211.

13. Zhang Q, Bastard P, Bolze A, Jouanguy E, Zhang S-Y, Cobat A, Notarangelo LD, Su HC, Abel L, Casanova J-L. Life-threatening COVID-19: defective interferons unleash excessive inflammation. Med. 2020;1(1):14-20. https://doi.org/10.1016/j.medj.2020.12. 001.

14. Bastard, P.; Gervais, A.; Le Voyer, T.; Rosain, J.; Philippot, Q.; Manry, J.; Michailidis, E.; Hoffmann, H.-H.; Eto, S.; Garcia-Prat, M.; Bizien, L.; Parra-Martínez, A.; Yang, R.; Haljasmägi, L.; Migaud, M.; Särekannu, K.; Maslovskaja, J.; de Prost, N.; Tandjaoui-Lambiotte, Y.; Luyt, C.-E.; Amador-Borrero, B.; Gaudet, A.; Poissy, J.; Morel, P.; Richard, P.; Cognasse, F.; Troya, J.; TrouilletAssant, S.; Belot, A.; Saker, K.; Garçon, P.; Rivière, J. G.; Lagier, J.-C.; Gentile, S.; Rosen, L. B.; Shaw, E.; Morio, T.; Tanaka, J.; Dalmau, D.; Tharaux, P.-L.; Sene, D.; Stepanian, A.; Megarbane, B.; Triantafyllia, V.; Fekkar, A.; Heath, J. R.; Franco, J. L.; Anaya, J.-M.; Solé-Violán, J.; Imberti, L.; Biondi, A.; Bonfanti, P.; Castagnoli, R.; Delmonte, O. M.; Zhang, Y.; Snow, A. L.; Holland, S. M.; Biggs, C.; Moncada-Vélez, M.; Arias, A. A.; Lorenzo, L.; Boucherit, S.; Coulibaly, B.; Anglicheau, D.; Planas, A. M.; Haerynck, F.; Duvlis, S.; Nussbaum, R. L.; Ozcelik, T.; Keles, S.; Bousfiha, A. A.; El Bakkouri, J.; Ramirez-Santana, C.; Paul, S.; Pan-Hammarström, Q.; Hammarström, L.; Dupont, A.; Kurolap, A.; Metz, C. N.; Aiuti, A.; Casari, G.; Lampasona, V.; Ciceri, F.; Barreiros, L. A.; Dominguez-Garrido, E.; Vidigal, M.; Zatz, M.; van de Beek, D.; Sahanic, S.; Tancevski, I.; Stepanovskyy, Y.; Boyarchuk, O.; Nukui, Y.; Tsumura, M.; Vidaur, L.; Tangye, S. G.; Burrel, S.; Duffy, D.; Quintana-Murci, L.; Klocperk, A.; Kann, N. Y.; Shcherbina, A.; Lau, Y.-L.; Leung, D.; Coulongeat, M.; Marlet, J.; Koning, R.; Reyes, L. F.; Chauvineau-Grenier, A.; Venet, F.; Monneret, G.; Nussenzweig, M. C.; Arrestier, R.; Boudhabhay, I.; Baris-Feldman, H.; Hagin, D.; Wauters, J.; Meyts, I.; Dyer, A. H.; Kennelly, S. P.; Bourke, N. M.; Halwani, R.; Sharif-Askari, N. S.; Dorgham, K.; Sallette, J.; Sedkaoui, S. M.; AlKhater, S.; Rigo-Bonnin, R.; Morandeira, F.; Roussel, L.; Vinh, D. C.; Ostrowski, S. R.; Condino-Neto, A.; Prando, C.; Bonradenko, A.; Spaan, A. N.; Gilardin, L.; Fellay, J.; Lyonnet, S.; Bilguvar, K.; Lifton, R. P.; Mane, S.; HGID Lab§; COVID Clinicians§; COVID-STORM Clinicians§; NIAID Immune Response 
to COVID Group§; NH-COVAIR Study Group§; Danish CHGE§; Danish Blood Donor Study§; St. James's Hospital; SARS CoV2 Interest group§; French COVID Cohort Study Group§; Imagine COVID-Group\$; The Milieu Intérieur Consortium§; CoVContact Cohort§; Amsterdam UMC Covid-19; Biobank Investigators $\$$; COVID Human Genetic Effort§; CONSTANCES cohort§; 3C-Dijon Study§; Cerba Health-Care§; Etablissement du Sang study group§; Anderson, M. S.; Boisson, B.; Béziat, V.; Zhang, S.-Y.; Vandreakos, E.; Hermine, O.; Pujol, A.; Peterson, P.; Mogensen, T. H.; Rowen, L.; Mond, J.; Debette, S.; de Lamballerie, X.; Duval, X.; Mentré, F.; Zins, M.; Soler-Palacin, P.; Colobran, R.; Gorochov, G.; Solanich, X.; Susen, S.; MartinezPicado, J.; Raoult, D.; Vasse, M.; Gregersen, P. K.; Piemonti, L.; Rodríguez-Gallego, C.; Notarangelo, L. D.; Su, H. C.; Kisand, K.; Okada, S.; Puel, A.; Jouanguy, E.; Rice, C. M.; Tiberghien, P.; Zhang, Q.; Cobat, A.; Abel, L.; Casanova, J.-L. Autoantibodies neutralizing type I IFNs are present in $\sim 4 \%$ of uninfected individuals over 70 years old and account for $20 \%$ of COVID-19 deaths. Sci. Immunol. 2021, 6 (62), eabl4340. https://doi.org/10.1126/ sciimmunol.abl4340.

15. Region, L. P. La surmortalité durant l'épidémie de Covid-19 dans les départements franciliens https://www.ors-idf.org/nos-travaux/ publications/la-surmortalite-durant-lepidemie-de-covid-19-dansles-departements-franciliens/ (accessed 2021 -09 -09).

16. Rossi B, Nguyen LS, Zimmermann P, Boucenna F, Dubret L, Baucher L, Guillot H, Bouldouyre M-A, Allenbach Y, Salem J-E, Barsoum P, Oufella A, Gros H. Effect of tocilizumab in hospitalized patients with severe COVID-19 pneumonia: a case-control cohort study. Pharmaceuticals. 2020;13(10):317. https://doi.org/ 10.3390/ph13100317.

17. Clinical Spectrum https://www.covid19treatmentguidelines.nih. gov/overview/clinical-spectrum/ (accessed 2021 -09-14).

18. Meager A, Visvalingam K, Peterson P, Möll K, Murumägi A, Krohn K, Eskelin P, Perheentupa J, Husebye E, Kadota Y, Will$\operatorname{cox} \mathrm{N}$. Anti-interferon autoantibodies in autoimmune polyendocrinopathy syndrome type 1. PLoS Med. 2006;3(7): e289. https:// doi.org/10.1371/journal.pmed.0030289.

19. Kärner J, Meager A, Laan M, Maslovskaja J, Pihlap M, Remm A, Juronen E, Wolff ASB, Husebye ES, Podkrajšek KT, Bratanic N, Battelino T, Willcox N, Peterson P, Kisand K. Anti-cytokine autoantibodies suggest pathogenetic links with autoimmune regulator deficiency in humans and mice: anti-cytokine autoantibodies in mice and humans. Clin Exp Immunol. 2013;171(3):263-72. https://doi.org/10.1111/cei.12024.

20. Bastard P, Orlova E, Sozaeva L, Lévy R, James A, Schmitt MM, Ochoa S, Kareva M, Rodina Y, Gervais A, Le Voyer T, Rosain J, Philippot Q, Neehus A-L, Shaw E, Migaud M, Bizien L, Ekwall O, Berg S, Beccuti G, Ghizzoni L, Thiriez G, Pavot A, Goujard C, Frémond M-L, Carter E, Rothenbuhler A, Linglart A, Mignot B, Comte A, Cheikh N, Hermine O, Breivik L, Husebye ES, Humbert S, Rohrlich P, Coaquette A, Vuoto F, Faure K, Mahlaoui N,
Kotnik P, Battelino T, Trebušak Podkrajšek K, Kisand K, Ferré EMN, DiMaggio T, Rosen LB, Burbelo PD, McIntyre M, Kann NY, Shcherbina A, Pavlova M, Kolodkina A, Holland SM, Zhang S-Y, Crow YJ, Notarangelo LD, Su HC, Abel L, Anderson MS, Jouanguy E, Neven B, Puel A, Casanova J-L, Lionakis MS. Preexisting autoantibodies to type I IFNs underlie critical COVID19 pneumonia in patients with APS-1. J Exp Med. 2021;218(7): e20210554. https://doi.org/10.1084/jem.20210554.

21. Meager A, Wadhwa M, Dilger P, Bird C, Thorpe R, NewsomDavis J, Willcox N. Anti-cytokine autoantibodies in autoimmunity: preponderance of neutralizing autoantibodies against interferon-alpha, interferon-omega and interleukin-12 in patients with thymoma and/or myasthenia gravis: cytokine autoantibodies, thymoma and myasthenia gravis. Clin Exp Immunol. 2003;132(1):128-36. https://doi.org/10.1046/j.1365-2249.2003. 02113.x.

22. Howe HS, Leung BPL. Anti-cytokine autoantibodies in systemic lupus erythematosus. Cells. 2019;9(1):72. https://doi.org/10.3390/ cells9010072.

23. Morimoto AM, Flesher DT, Yang J, Wolslegel K, Wang X, Brady A, Abbas AR, Quarmby V, Wakshull E, Richardson B, Townsend MJ, Behrens TW. Association of endogenous anti-interferon- $\alpha$ autoantibodies with decreased interferon-pathway and disease activity in patients with systemic lupus erythematosus. Arthritis Rheum. 2011;63(8):2407-15. https://doi.org/10.1002/art.30399.

24. Gupta S, Tatouli IP, Rosen LB, Hasni S, Alevizos I, Manna ZG, Rivera J, Jiang C, Siegel RM, Holland SM, Moutsopoulos HM, Browne SK. Distinct functions of autoantibodies against interferon in systemic lupus erythematosus: a comprehensive analysis of anticytokine autoantibodies in common rheumatic diseases: anti-interferon functions in SLE. Arthritis Rheumatol. 2016;68(7):1677-87. https://doi.org/10.1002/art.39607.

25. Bastard, P.; Michailidis, E.; Hoffmann, H.-H.; Chbihi, M.; Le Voyer, T.; Rosain, J.; Philippot, Q.; Seeleuthner, Y.; Gervais, A.; Materna, M.; de Oliveira, P. M. N.; Maia, M. de L. S.; Dinis Ano Bom, A. P.; Azamor, T.; Araújo da Conceição, D.; Goudouris, E.; Homma, A.; Slesak, G.; Schäfer, J.; Pulendran, B.; Miller, J. D.; Huits, R.; Yang, R.; Rosen, L. B.; Bizien, L.; Lorenzo, L.; Chrabieh, M.; Erazo, L. V.; Rozenberg, F.; Jeljeli, M. M.; Béziat, V.; Holland, S. M.; Cobat, A.; Notarangelo, L. D.; Su, H. C.; Ahmed, R.; Puel, A.; Zhang, S.-Y.; Abel, L.; Seligman, S. J.; Zhang, Q.; MacDonald, M. R.; Jouanguy, E.; Rice, C. M.; Casanova, J.-L. Auto-antibodies to type I IFNs can underlie adverse reactions to yellow fever live attenuated vaccine. J. Exp. Med. 2021, 218 (4), e20202486. https://doi.org/10.1084/jem.20202486.

Publisher's Note Springer Nature remains neutral with regard to jurisdictional claims in published maps and institutional affiliations. 